\title{
DESENVOLVIMENTO, MEIO AMBIENTE E DIREITOS DOS ÍNDIOS: DA NECESSIDADE DE UM NOVO ETHOS JURÍDICO
}

\author{
Violeta Refkalefsky Loureiro ${ }^{1}$
}

DEVELOPMENT, ENVIRONMENT AND INDIAN RIGHTS: WHERE IS THE PRIORITY?

\section{RESUMO}

DISCUTE ASPECTOS DA POLÍTICA INDIGENISTA BRASILEIRA RECENTE, DESTACANDO A POSIÇÃO OSCILANTE DO ESTADO E SUA POSTURA AO LONGO DA HISTÓRIA, ADVERSA À CONVIVÊNCIA COM GRUPOS SOCIAIS MULTICULTURAIS, EM ESPECIAL COM OS GRUPOS INDÍGENAS. ApESAR dO DISPOSTO NA CONSTITUIÇÃO BRASILEIRA DE 1988 QUANTO AOS DIREITOS DOS ÍNDIOS E À PRESERVAÇÃO DE SUAS CULTURAS, SETORES DA SOCIEDADE CIVIL E ESTADO, SEGUIDAS VEZES, DEMONSTRAM ENCARÁ-LOS COMO AMEAÇAS À UNIDADE E À SEGURANÇA NACIONAL, QUANDO SITUADOS EM ÁREAS DE FRONTEIRA; OU COMO ENTRAVES AO DESENVOLVIMENTO NACIONAL. IDENTIFICA TRÊS LINHAS BÁSICAS DE PENSAMENTO FACE À QUESTÃO INDÍGENA: EM FAVOR DA INTEGRAÇÃO (COMPULSÓRIA OU NÃO DOS ÍNDIOS), A QUE DEFENDE OS DIREITOS A UMA CULTURA DIFERENTE DA HEGEMÔNICA E UMA TERCEIRA, À QUAL DÁ DESTAQUE. TRATA-SE DE UM DESLOCAMENTO DO EIXO DA QUESTÃO - DA IDENTIDADE INDÍGENA, ANTES QUESTIONADA, PARA UMA DISCUSSÃO SOBRE A TERRA, COMO SE ESTA FOSSE UM ELEMENTO DESCOLADO DA CULTURA INDÍGENA. DESTACA A RESPONSABILIDADE AO JUDICIÁRIO (ESPECIALMENTE DO STF), QUANTO AOS DIREITOS DOS ÍNDIOS À MULTICULTURALIDADE DENTRO DO ESPAÇO

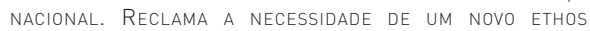
JURÍDICO-SOCIAL PARA TRATAR A QUESTÃO INDÍGENA.

\section{PALAVRAS-CHAVE}

DIREITO INDÍGENA; TERRA INDÍGENA; POLÍTICA INDIGENISTA.

\section{ABSTRACT}

IT DEALS WITH THE RECENT BRAZILIAN INDIAN POLITIC, SHOWING IN ITS ANALYSIS THE OSCILLATING POSITION OF THE STATE AND ITS ADVERSE POSITION ALONG THE HISTORY, AS TO ITS ACQUAINTANCESHIP WITH THE MULTICULTURAL GROUPS, ESPECIALLY WITH INDIAN GROUPS. IN SPITE OF THE 1988 BRAZILIAN CONSTITUTION RULE REGARDING THE INDIAN RIGHTS AND THE PRESERVATION OF THE INDIAN CULTURE, SECTIONS OF THE CIVIL SOCIETY AND OF THE STATE HAVE SEEN THEM, SEVERAL TIMES, AS THREATS TO ITS UNITY AND NATIONAL SECURITY AS WELL; SPECIALLY AROUND THE BORDERING AREAS OR SOMETIMES SEEN AS HINDRANCES TO THE NATIONAL DEVELOPMENT. THREE BASIC THOUGHTS REGARDING THE INDIANS HAVE BEEN IDENTIFIED: ONE IN FAVOUR OF THE INDIAN INTEGRATION (COMPULSORY OR NOT): THE OTHER REFERS TO THE PROTECTION OF THEIR RIGHTS TO HAVE A CULTURE DIFFERENT FROM THE HEGEMONIC ONE; AND A THIRD ONE TO BE OUTSTANDING. THIS ONE TRANSFERS THE MAIN POINT OF THE INDIAN IDENTITY WHICH HAS BEEN QUESTIONED BEFORE TO THE QUESTION RELATED TO THE INDIAN LAND AS IF THE LAND DIDN'T TAKE PART OF THEIR CULTURE. SHOWS THE RESPONSIBILITY OF THE JUDICIARY (SPECIALLY THIS ONE OF THE STF) ABOUT THE GARANTEE OF THE INDIAN RIGHTS TO ITS CULTURE WITHIN THE NATIONAL AREA. THEREFORE THE NECESSITY FOR A NEW SOCIAL-JURIDICAL ETHOS TO DEAL WITH INDIAN PROBLEMS HAS BEEN CLAIMED.

\section{KEYWORDS}

INDIAN RIGHTS; INDIAN LAND; POLITICS FOR INDIANS. 


\section{INTRODUÇÃO}

A história evidencia que o Estado, as elites e mesmo uma parte expressiva da sociedade brasileira jamais aceitaram conviver, com tranquilidade, com culturas diferentes e grupos minoritários dentro do território nacional, respeitando-os em sua autonomia e dignidade próprias. As políticas indigenistas concebidas têm desencadeado ações de caráter ambíguo e, muitas vezes contraditório, ao longo da formação histórica do País, que se estende do período colonial aos dias atuais. Elas são inspiradas em posturas teórico-filosóficas distintas.

A postura assimilacionista (mas também a evolucionista, que leva às mesmas consequências da anterior), tem predominado desde que, no século XVIII, o Marquês de Pombal instituiu este procedimento nos Diretórios dos Índios (documentos emanados da Corte portuguesa, que consagravam a forma de tratar e se relacionar com os índios). Em sua longa gestão Pombal estimulava o casamento entre portugueses e índias, como estratégia política de povoamento e desenvolvimento da Colônia, o que consolidou grandemente a ideia de integração à sociedade maior e da "evolução" dos índios, decorrente do casamento com brancos. As missões religiosas, seja no período colonial, seja posteriormente (e elas existem até hoje na região), seguem na mesma direção - alterando-lhes a cultura e "civilizando-os"; o mesmo ocorreu durante a existência do SPI - Serviço de Proteção aos Índios, órgão que antecedeu a Funai.

A ideia de integração do índio à sociedade nacional funda-se, portanto, em princípios ético-valorativos de origem mais que secular, que pregam o assimilacionismo cultural do índio à sociedade maior como algo necessário, inevitável e como resultado do inexorável progresso das sociedades ocidentais. É que o pensamento moderno assimilou, desde o Iluminismo, importantes princípios, dentre os quais se destacam : a ideia de progresso e de evolução permanentes das sociedades; e a crença na capacidade da ciência que, além de trazer incontáveis benefícios à humanidade, seria capaz inclusive, de sanar problemas involuntários e inesperados, gerados por ela própria (HORKHEIMER-ADORNO, 1980). essa corrente se sustenta numa vertente de caráter ideológico: a ideia, ora clara ora disfarçada - de que a forma de vida da moderna sociedade ocidental é mais desenvolvida, melhor e, por isto, hierarquicamente superior à das minorias étnicas; assim sendo, ser assimilado por ela significa "evoluir", "progredir", passando a integrar o mundo moderno, podendo então gozar dos avanços da civilização. Em consequência, se os índios não aderem ao progresso inevitável da sociedade industrial que esta linha defende, num embate entre as duas culturas (uma civilizada e a outra supostamente arcaica), a forma de vida da sociedade ocidental e moderna teria prevalência sobre a das minorias étnicas. O progresso da cultura moderna não pode ser impedido ou dificultado por causa delas, em detrimento do bem-estar dos ditos civilizados - os que, implícita ou explicitamente, se consideram como partícipes e portadores de uma cultura superior. E se grande parte das ações que visava o assimilacionismo dos índios foi, aparentemente abandonada 
após a ditadura militar (1964/85), a ideia da assimilação dos índios pela sociedade nacional permanece viva em numerosos setores da vida política brasileira e, em especial nas políticas públicas de caráter desenvolvimentista.

O Estatuto do Índio (Lei no. 6001, de 1973), concebido no período da ditadura militar, à luz do projeto de um Brasil Grande, desenvolvido e hegemônico na América Latina -, continua vigindo até os dias atuais, em completo desacordo com o disposto na Constituição brasileira de 1988. Em seu artigo primeiro, ele "regula a situação jurídica dos índios e silvícolas e das comunidades indígenas, com o propósito de preservar sua cultura e integrá-los (sic), progressiva e harmoniosamente, à comunidade nacional". Tal dispositivo carrega consigo uma contradição essencial: ou se preserva a cultura em sua integralidade, com seu caráter identitário, tal como dispõe a Carta Magna, ou ela fica subsumida se assimilada à sociedade; mas as duas posturas não podem conviver simultaneamente como linhas balizadoras das políticas públicas.

Em um outro extremo, situa-se a linha teórico-ideológica (com as políticas que a ela se vinculam) francamente oposta à primeira. A esta forma de pensar aderem os que reconhecem os índios como culturas próprias e defendem suas maneiras diferenciadas de viver em seu habitat e em suas respectivas terras. Ela se mostra em favor da proteção dos direitos indígenas coletivos, o que implica na defesa da terra. Mas esses direitos não se restringem a ela; estendem-se aos direitos humanos fundamentais, aos econômicos, sociais, culturais e ambientais, sem os quais a cultura indígena não tem condições de sobreviver. E é este o espírito da Constituição de 1988 quando reconhece e garante o direito à multiculturalidade e o respeito às minorias.

Esta segunda linha de pensamento é claramente minoritária. Pode-se constatar isto através do grande e frequente número de ações que afetam os grupos indígenas, sejam elas de iniciativa do Estado ou de particulares. Em contrapartida, os protestos contra essas ações são raros e localizados, partindo em geral, de organizações específicas de defesa dos índios ou dos direitos humanos, sem motivar e mobilizar segmentos mais amplos da sociedade civil.

$\mathrm{E}$, finalmente, uma terceira postura, que designo pelo termo versão nova de uma velha ideia. Trata-se de uma variante da corrente assimilacionista, embora apresentada sob um discurso renovado e aparentemente neutro em relação às minorias indígenas. Mesmo não se negando a reconhecer as diferenças étnico-culturais do povo brasileiro (o que evita parecer retrógrada ou afrontar a lei), ela é tão danosa quanto a primeira. Embora não conteste o direito à diferença, argumenta pela desnecessidade de terras extensas para os índios. Apresenta-se com uma frequência cada vez maior e se funda em vários pressupostos nos quais a rejeição ao índio fica desfocada ou deslocada, já que os elementos argumentativos passam a girar exclusivamente em torno de três pontos: a) a extensão da terra indígena; b) a aspiração ao desenvolvimento econômico (independentemente da forma como ele se processe); c) e a pressuposição de que os dois pontos anteriores são incompatíveis. Esta posição esconde o preconceito e 
intolerância cultural, quando centra a discussão na terra, evitando sempre questionar a identidade indígena, já que esta é garantida por lei. Amplos setores da elite entendem que o País não pode "desperdiçar" terras com segmentos minoritários da sociedade que não geram impostos e imobilizam terras que seriam mais produtivas com outra e melhor destinação econômica; além disso, as terras indígenas representariam obstáculos frente a empreendimentos produtivos de particulares ou de infraestruturas pretendidas pelo Estado.

\section{DUAS CONCEPÇÕES SOBRE A TERRA:} UM RECURSO NATURAL OU UM LUGAR DE VIDA E CULTURA

Pode-se identificar duas lógicas ou racionalidades distintas que orientam e movem segmentos da sociedade brasileira com posições e interesses antagônicos frente à terra indígena: uma racionalidade desenvolvimentista, de caráter exclusivamente econômico, que visa o mercado e a geração do lucro individual, já que a terra é considerada como um simples recurso natural sujeito à exploração; e uma outra, de natureza comunitária, que valoriza os direitos humanos, respeita a pluriculturalidade da Nação brasileira e entende a terra indígena como lugar de vida e cultura. O predomínio da primeira fica claro quando as elites e grupos econômicos não protestam, e mesmo valorizam o sucesso de empresários que, assumindo uma vasta extensão de terra, exploram-na em benefício próprio e assim acumulam e concentram capitais; mas questionam a legitimidade da terra indígena quando ela é igualmente extensa (proporcionalmente ao número de beneficiários). ${ }^{2}$ E mais claro ainda, a cada momento histórico em que, na Amazônia, projetos de impacto sobre culturas indígenas são considerados como prioritários, porque portam consigo a mensagem do progresso e do desenvolvimento.

Da década de 1970 aos dias atuais, os habitantes da região vivenciam as consequências dos numerosos exemplos de agressões e violações de direitos das minorias que nela habitam (em especial índios e populações tradicionais); estas questões vem sendo fartamente estudadas, denunciadas pela imprensa e por organizações de defesa dos direitos humanos (desde a Transamazônica no início dos anos 1970, à atual hidrelétrica de Belo Monte, ambas no Pará). E constatado que, além de seus numerosos efeitos perversos, essas ações não tem trazido o desenvolvimento esperado. ${ }^{3}$

As duas racionalidades (de mercado e comunitária) estão igualmente presentes no Judiciário, razão pela qual este decide, ora movido pela lógica de natureza econômica, ora buscando respeito a uma democracia profunda e humanizada, que leva em conta a identidade coletiva e a herança cultural dos grupos sociais diferenciados. Mas, é principalmente na prática cotidiana do aparelho administrativo-burocrático do Estado (e isto ocorre nas três esferas), que a integração forçada dos índios vem se processando. Isto porque são as ações concernentes às políticas públicas desenvolvimentistas do Executivo (as quais, com muita frequência, recebem o apoio do Judiciário, noutras se 
processam como simples rotina dos órgãos), que acabam prevalecendo sobre a integridade das culturas e terras indígenas; ou resultam de ações de particulares, que passam ao largo do Judiciário. Deve-se também levar em conta, que parte das decisões oscilantes do Judiciário face à matéria não decorre somente de posições ético-ideológicas distintas de quem julga, sentencia ou revoga um ato, ora a favor, ora contra o mesmo nas diversas instâncias, mas de contradições entre dispositivos legais, especialmente entre os de proteção ambiental e os indígenas (tratadas noutro item), que (des)norteiam as políticas dos órgãos. Mas, em todos os casos, a terra é atingida.

\section{VELHAS HERANÇAS NUM BRASIL NOVO: A CONSOLIDAÇÃO DO ESPAÇO NACIONAL}

A construção política do Estado brasileiro implicou, em todas as épocas, em esforços de várias ordens. O primeiro e mais persistente parece ter sido aquele relativo à formação e à dominação territoriais, dando continuidade às práticas expansionistas e de controle do território que caracterizaram a história do Brasil colonial. A expansão territorial marcou profundamente a vida política brasileira, estendendo-se até o século XX, quando a questão do Acre desacelera a expansão pela via das fronteiras externas. Mas prosseguiu até os dias atuais, através da dominação interna exercida sobre as terras dos diferentes povos que ocupam os espaços do solo nacional, especialmente os índios.

O enfoque exacerbado na consolidação do território levou a que a formação da sociedade brasileira ficasse subsumida grandemente à questão territorial. O Estado tomou para si, em prioridade, a missão relativa à geopolítica de controle das terras e foi, gradativamente, delegando poderes às elites ou facilitando a elas a consolidação dessa meta em seu favor. Assim, Estado e elites durante o período de quase dois séculos que se estende da Independência aos dias atuais, exerceram o controle quase absoluto sobre a distribuição de terras no Brasil, através de dispositivos e procedimentos legais, administrativos e burocráticos. E o fizeram de forma antidemocrática, do que resultou uma estrutura social fortemente distorcida (SCHWARTZMAN, 1988). $\mathrm{Na}$ verdade, isto ocorreu durante todo o período colonial, estendendo-se como traço político-social do Brasil moderno, conforme demonstrou Raymundo Faoro (FAORO, 1975) numa obra clássica sobre a questão. Para o Estado brasileiro as terras (e os recursos naturais) tem sido consideradas historicamente como mais importantes que os povos que nelas se estabeleceriam e nelas construiriam suas vidas.

\section{Velhas heranças num Brasil nOvo: O Mito do POVO ÚNico}

Outro esforço, igualmente marcante, refere-se à formação de uma imaginada identidade nacional, que acompanhou a construção do Brasil como nação desde a 
Independência. Esta identidade pressupunha pelo menos três vetores norteadores: (a) a busca persistente da constituição de um povo único - o povo brasileiro, embora este seja puramente idealizado (ALVES, 2005); (b) a negação sistemática do reconhecimento da multiculturalidade dos diferentes povos que integram a sociedade nacional (RIBEIRO, 1970); (c) um tratamento desigual, inferiorizante de índios (e negros) em relação à população branca, que assumiu e, às vezes assume formas violentas, chegando ao massacre em numerosos casos (VIDAL,1977; MARTINS, 1997; RICARDO, 1996, 2000).

A ideia de uma nação formada por vários povos distintos, compartilhando o mesmo espaço nacional foi sempre rejeitada, por ser compreendida como uma oposição à unidade nacional e uma ameaça à segurança nacional. No caso dos índios, em especial, além da diferença cultural pela qual são frequentemente vistos como estranhos, perigosos e bárbaros, eles têm sido também estigmatizados pela condição de representantes do atraso, do primitivismo, enfim, por serem povos que estariam, por suas próprias existências, negando a entrada do Brasil na modernidade do mundo ocidental na qual o País pretende se inserir (LOUREIRO, 1992).

\section{A fronteira eConômica aVAnÇa sobre populações tradicionais E GRUPOS INDÍGENAS COM A PROMESSA DO DESENVOLVIMENTO DA REGIÃO}

A integração forçada dos índios à sociedade nacional é clara, algumas vezes, implícitas noutras. Resulta de uma série de fatores combinados: o mito de um povo único, a inaceitação da multiculturalidade; mas, a partir da década de 1970 ela se deve também (e muito fortemente), à ideologia do progresso e do desenvolvimento (sem atenuantes). E, em consequência, o uso da terra como recurso natural explorável, nutre as ações governamentais (através dos grandes projetos de infraestruturas). E a Amazônia, como fronteira de recursos tem sido o lócus privilegiado dessa exploração. Ou de empresários que expandem a fronteira de recursos em várias direções: Roraima; sudeste, sul e oeste do Pará; sul de Rondônia, sul do Tocantins, parte do Amapá e Acre. ${ }^{4}$ A fronteira avança estimulada, principalmente por novas atividades produtivas para o mercado global - as chamadas commodities, como os grãos, especialmente a soja, a siderurgia a carvão vegetal e outras, que atraem migrantes; a eles se somam os que buscam emprego em frentes de desmatamento, garimpos, grilagem e venda de terras e outras atividades legais ou ilegais, geridas por novos capitais. E estes em suas marchas de penetração deparam-se com os índios. A fricção é inevitável. A expansão dessas atividades vem acompanhada de conflitos. Roraima é o caso mais exemplar. Enquanto a população era reduzida, não havia conflitos e as terras indígenas jamais tinham sido questionadas. O problema se instalou depois que intensas correntes migratórias do nordeste do Brasil e do Rio Grande do Sul, a partir da década de 1980, procuraram aquelas terras como novo lugar de fixação, com ativi- 
dades de uso extensivo como o plantio de arroz ou projetos de assentamento. Em menos de 30 anos, a população cresceu mais de 400\%, passando de 79.159 em 1980 a 412.783 habitantes em 2008 (IBGE/estimativa), sendo a mais recente frente de expansão da fronteira econômica da região. $\mathrm{O}$ avanço sobre as terras indígenas intensificou-se e a oposição entre a atividade econômica e o "primitivismo" dos índios instalou-se na vida do estado.

\section{OS ÍNDIOS COMO AMEAÇA À INTEGRIDADE NACIONAL}

Alguns segmentos da sociedade, partidários da linha integracionista, defendem a fragmentação das terras indígenas contínuas quando em áreas de fronteiras, em especial aquelas que se estendem sobre dois países contíguos (é o caso de vários grupos indígenas da região). Enxergam aí um elemento facilitador da independência dos grupos indígenas, constituindo-se, portanto, em ameaça à soberania nacional, por conferir a eles a possibilidade de se estruturar, no futuro, como territórios independentes, formando novas nações; daí as tentativas de evitar tais continuidades de terras. Também neste caso Roraima apresenta a situação mais conflitada porque de suas 32 terras indígenas, que totalizam $103.415 \mathrm{~km}^{2}$, apenas três não se localizam em área de fronteira. ${ }^{5}$

$\mathrm{O}$ argumento de um suposto separatismo retorna ciclicamente. Ele foi fartamente veiculado pela mídia em desfavor da homologação da terra dos Yanomami na década de 1990, assim como no conflitado caso Raposa Serra do Sol, também em Roraima (na fronteira com a Venezuela e a Guiana), habitada por 18.992 índios de 5 etnias - Macuxi, Tapamona, Wapixana, Ingaricó e Taurepang. Elites locais, autoridades (governador, senador, prefeitos), deslocaram-se a Brasília para prevenir o Congresso, o Judiciário e a imprensa sobre a possibilidade de se criar ali o embrião de um território independente. Daí porque propuseram a fragmentação da área em partes descontínuas. Ora, obstaculizar ou fazer restrições à demarcação de uma terra contínua, fracionando-a em áreas menores dificulta a circulação dos índios quando de suas visitas a parentes noutras malocas, assim como a participação em festas, colheitas, rituais etc, já que um fazendeiro de soja, arroz ou outra cultura, instalado nos interstícios das partes fragmentadas não permitirá que índios circulem em suas plantações e, menos ainda, que abram caminhos entre elas para se locomover de uma fração de terra a outra.

Some-se a isto o fato de que a fragmentação vai na direção oposta do que recomenda o parágrafo 2 da Declaração das Nações Unidas sobre os Direitos dos Povos Indígenas, da qual o Brasil é signatário, quando esta dispõe que os Estados devem facilitar a circulação dos índios entre si para preservar suas culturas. Por fim, nega direitos e desrespeita o referido tratado internacional que, em seu Artigo 36, assim dispõe: 
1. Os povos indígenas, em particular os que estão divididos por fronteiras internacionais, têm o direito de manter e desenvolver contatos, relações e cooperação, incluindo atividades de caráter espiritual, cultural, político, econômico e social, com seus próprios membros, assim como com outros povos através das fronteiras. 2. Os Estados, em consulta e cooperação com os povos indígenas, adotarão medidas eficazes para facilitar o exercício e garantir a aplicação desse direito.

Em Roraima, fazendeiros protestaram, queimaram pontes, obstruíram estradas e ameaçaram defender com armas as terras conquistadas aos índios, para legitimar a situação das fazendas de apenas seis grandes produtores de arroz. Políticos mobilizaram a mídia e a população urbana. Os fazendeiros questionaram as terras na justiça, chegando ao STF em meio a conflitos e divisões internas, em protestos que ganharam repercussão nacional. O Judiciário se viu pressionado pela rebeldia, a afronta, a força do poder político e econômico e as adesões que as partes contrárias à demarcação contínua conseguiram. Mas optou pelo direito dos índios, ao invés de negar-lhes isso, influenciado por um imaginário temor de independência ou pela força do capital. Sobre a questão o Ministro-relator do Supremo Tribunal Federal-STF, Carlos Ayres de Brito, ao apresentar em 2008 seu voto expressou um irrefutável ponto de vista: "é preciso que o Estado brasileiro defenda os direitos à vida, à natureza e à cultura dos seus índios para que eles queiram o Brasil como o país para ser o deles e (queiram nele) viver para todo o sempre”. O episódio evidenciou a responsabilidade do Estado de salvaguardar o direito dos índios de viver em suas terras, sejam elas fronteiriças ou não; e se o fato não for paradigmático como conduta para casos futuros, é emblemático em termos de posição do Judiciário superior quanto à matéria.

\section{A REDUÇÃO DA TERRA OU REMOÇÃO DE ÍNDIOS IMPLICA NA PERDA DA CULTURA E DA IDENTIDADE}

A questão da terra envolve e afeta, profundamente, a identidade cultural do índio, posto que a cultura indígena não se dissocia da natureza em que eles vivem. E não apenas em relação aos mitos, embora estes possam ajudar a compreender suas relações com a natureza. Os Ianomami, por exemplo, entendem a floresta como uma região habitada por espíritos guardiões (os de seus antepassados). Dependendo da forma como eles tratem a floresta em que estes vivem, a natureza será mais pródiga, menos pródiga ou mesmo avara; e eles, por sua vez, serão beneficiados com saúde e fartura, ou penalizados com escassez e doenças. Há portanto, uma integração profunda entre índios e natureza e uma continuidade nesta integração mútua. Ser índio é ser índio enquanto ser inserido na natureza. E é da inseparabilidade desses dois elementos combinados que se origina uma cultura própria - a sua. 
A redução da terra indígena pela perda de partes dela, seja como decorrência da disputa do capital sobre elas, seja como consequência da ideologia de integração dos índios à sociedade nacional como um processo "natural" e irrenunciável, seja através da remoção, implica, de início, em doenças e mortes que, certamente, diminuirão o contingente populacional já minoritário. ${ }^{6} \mathrm{O}$ mesmo ocorre quando o ecossistema é alterado pelo impacto de grandes obras, cortado por estradas ou diminuído. Estudos (ORLOVE; BRUSH, 1996) mencionam que as políticas de conservação da natureza incluem três níveis de esforços: (a) preservar espécies específicas; (b) estabelecer áreas reservadas; (c) proteger ecossistemas, diminuindo o mais possível os hiatos entre as partes. Num segundo momento, e a história vem demonstrando isto, implica na perda da biodiversidade nesses espaços reduzidos ou alterados. O mesmo ocorre quanto às áreas fragmentadas, descontinuadas.

Como consequência da redução ou da fragmentação de uma área antes contínua, pela interferência de estradas, fazendas de gado ou por outros motivos, segue-se o risco ou a perda efetiva das condições de sobrevivência com base nos costumes tradicionais, a diminuição da biodiversidade pelo empobrecimento da natureza, a escassez de produtos alimentares e dos elementos da medicina indígena - dependente do aproveitamento de produtos da floresta -, a contaminação de cursos d'água por inseticidas oriundos de culturas que se instalam às proximidades e por outras razões.

Por fim, também as manifestações culturais como festas, rituais, práticas alimentares, organização da família e do trabalho ficam dificultados ou impossibilitados de se exercerem plenamente. A lógica que sustenta o comportamento e os valores dos índios privilegia a conservação da biodiversidade do ecossistema em que vivem e onde desenvolvem sua cultura. Trata-se de uma lógica diferente daquela que é hegemônica no mundo ocidental - mercadológico e industrializado -, razão porque nem sempre as demandas dos índios são compreendidas e acabam por se afigurar como descabidas ou intransigentes.

A remoção de grupos indígenas também não se processa sem dificuldades. Em primeiro lugar, ela implica no abandono de lugares sagrados, onde residem os espíritos de seus antepassados e deuses. Em segundo lugar, o saber relativo à natureza - com a qual tem uma relação essencial e existencialmente associada - torna-se desnecessário e inútil noutro ambiente que não o seu próprio, onde esses saberes fazem sentido, têm utilidade, são reconhecidos e valorizados socialmente. O rompimento do elo milenar que os liga à terra e à natureza e do qual decorrem seus saberes e a partir dos quais articulam sua forma de vida, abala os índios não apenas física, mas também social e intelectualmente; ele provoca um vazio identitário e um visível desalento existencial, que tem sido claramente observado e pode ser constatado em grupos que, em décadas anteriores, vivenciaram ou vivenciam ainda este processo de perda, conforme estudos feitos por José de Souza Martins (MARTINS, 1997). Não há, portanto, a possibilidade, tantas vezes cogitada por não-índios, de que eles sobrevivam numa natureza pobre, 
numa terra de dimensão reduzida ou que sejam removidos para uma terra estranha, sem haver um sério comprometimento de suas culturas.

\section{DA AUdÁcia de PARTICULARES CONTRA A INTEGRIDADE DOS ÍNDIOS E} DA INCAPACIDADE DO ESTADO EQUACIONAR E DE MINIMIZAR PROBLEMAS À medida que a fronteira econômica avança na região, seja como decorrência das políticas governamentais, seja pela ação de terceiros, mais a integridade dos índios é ameaçada. Se poucas mediações tem sido intentadas no sentido de conciliar as questões, muitas tem sido as omissões do Estado, mesmo quanto a alterar projetos, buscando alternativas menos impactantes. São numerosas as situações conflituosas e complexas que decorrem das políticas dos órgãos governamentais nas diversas esferas político-administrativas, bem como a omissão quanto a ações de particulares, em especial no que tange à garimpagem, à extração de madeiras e à grilagem de terras, mesmo quando se trata da terra pública; governos municipais, com frequência, abrem estradas cortando ou margeando terras indígenas, o que facilita a entrada de posseiros e invasores de diversas ordens; órgãos federais e estaduais assentam colonos ou implantam infra-estruturas (estradas, hidrelétricas etc), obrigando à remoção de populações indígenas, quando soluções mitigadoras ou alternativas menos danosas poderiam ser discutidas e intentadas desde o momento da concepção dos projetos, isto é, bem antes que o conflito entre as partes já se houvesse instalado. Todas essas formas de agressão às culturas indígenas são frequentes e numerosas na região amazônica, que não cabe aqui relacioná-las. E pelo menos as de maior impacto acabam por bater às portas do Judiciário, movidas por grupos econômicos disputando interesses ou por pedidos de socorro de populações tradicionais ou minorias étnicas.

No caso do asfaltamento da rodovia Santarém-Cuiabá (BR-163), madeireiros e grileiros ameaçam os índios Parakanã e criam dificuldades para que a Funai realize seus trabalhos de demarcação e outros serviços na área, que já sofreu, recentemente, uma redução considerável. Em Óbidos (no Pará - Calha Norte do rio Amazonas), as terras dos índios Zoe, da terra indígena Tumucumaque e Paru d'Este, tem sido alvo de desmatamentos e os índios são ameaçados por madeireiros ${ }^{7}$. No Amapá os madeireiros entram em terras indígenas pela BR-156, que liga Macapá ao Oiapoque, já que a mesma faz limite com os povos Galibi Marworno, Karipunas e Palikur. Ainda no Amapá, o eixo da rodovia Perimetral Norte, que liga Macapá à Serra do Navio, corta terras dos Waiãpi e, quando beneficiada, propiciará, também, a entrada de madeireiros. ${ }^{8}$

Desde fins da década de 1980, empresas madeireiras entravam em terras indígenas dos Apiterewa-Parakanã para extrair madeira e, em alguns casos, o ouro. Na década de 1990, para agravar a já conflitiva situação, o próprio Incra doou terras indígenas dos Apiterewa-Parakanã, reconhecendo e legitimando terras invadidas e 
apropriadas por fazendeiros, marginais e aventureiros e destacando lotes da terra indígena para trabalhadores rurais, arregimentados às pressas, com a finalidade de simular um projeto de assentamento, quando a situação foi denunciada (PINTO, 2005, p. 157). ${ }^{9}$

Apesar do caos social e fundiário instalado na região, grandes empresas mineradoras continuam ampliando e multiplicando os projetos de exploração na área - sem serem obrigadas a corrigir o modelo implantado desde a ditadura militar - siderurgia a carvão vegetal, produção de minérios exportada sob a forma de semi-elaborados (lingotes), internalizando poucos benefícios, gerando poucos empregos, acarretando graves danos ambientais, em especial quanto ao desmatamento (ferindo abertamente a legislação vigente) e conflitando com populações tradicionais e índios. A disputa pela terra espelha o antagonismo que se estabelece entre as terras de uso comum, tradição imemorial, pouca ou nenhuma rentabilidade econômica e a ideologia do progresso e do desenvolvimento; embora o prometido e esperado desenvolvimento venha apresentando parcos resultados sociais. É o que os indicadores econômicos e sociais vem demonstrando há mais de três décadas, sem que o modelo econômico se altere em favor da região ou, ao menos, deixe de afrontar a legislação ambiental, preservando a natureza e a biodiversidade da região para o usufruto das gerações futuras (com as quais temos responsabilidade, hoje). ${ }^{10}$ Esses temas tem sido estudados cientificamente e fartamente denunciados, sem motivar uma ação enérgica do Executivo ou do Judiciário, no sentido de sustar empreendimentos que ferem leis ambientais e direitos humanos, salvo em casos muito específicos.

A postura ética que põe as terras como elemento central da disputa se exercita por variadas formas; uma delas é a simples execução de decisões do Judiciário que incidem sobre a redução das terras indígenas; ou quando este autoriza a execução de empreendimentos que afetam as populações, sem obrigar o Executivo a adotar alternativas menos danosas. É o caso da rodovia Santarém-Cuiabá, que afetará várias etnias, entre elas os Kaiapó e os Parakanã. Cabe perguntar por que, ao invés de uma rodovia, não foi cogitada a construção de uma ferrovia - que certamente, reduziria a ocupação populacional e a exploração madeireira às margens da estrada? Mapas de desmatamento da região do INPE/PRODES (Prog. de Monitoramento da Floresta Amazônica por Satélite) deixam evidentes as já extensas áreas desmatadas às margens da rodovia, antes mesmo de completar o asfaltamento da estrada; enquanto isto ocorre, os órgãos de terras dos Estados do Pará e de Mato Grosso recebem cotidianamente informações sobre o aumento da grilagem às margens da mesma.

Convém lembrar que é no exercício cotidiano do direito que as reivindicações objetivas dos grupos sociais podem ser socialmente asseguradas, estabelecendo uma ruptura positiva com o pesado passado de dívidas sociais que o Brasil acumulou. Escondidos nos processos e outros papéis que tramitam pelas diversas unidades e instâncias do Judiciário brasileiro encontram-se pessoas, vidas e destinos; e é no cotidiano 
da burocracia e pela via de papéis os mais diversos que o Direito pode construir uma dimensão societária, ampla e humanizada.

Mas é também pela via dos mesmos papéis que os direitos das pessoas podem converter-se em elementos reforçadores de desigualdades. E quando isto ocorre (e ocorre com frequência), a democracia real e a justiça social esperadas convertem-se apenas em ideias difusas e abstratas de democracia, que jazem confinadas nos textos teóricos, mas permanecem ausentes da vida social. E que reforçam um paradoxo tão conhecido da sociedade brasileira - quando se afirma que o país é dotado de uma legislação adequada, e mesmo avançada em muitos sentidos -, mas que não atende plenamente quando se trata de realizar, no cotidiano, uma justiça social mais inclusiva e plural, capaz de realizar os anseios dos pobres, dos marginalizados e dos etnicamente diferentes.

\section{As INCONGRUÊNCIAS DAS POLÍTICAS PROTECIONISTAS AUMENTAM O CAOS FUNDIÁRIO}

O agravamento da questão ambiental amazônica tem levado o Congresso e o Governo Federal a tomarem várias medidas. Uma delas foi a criação do Sistema Nacional de Proteção de Unidades de Conservação da Natureza - SNUC. ${ }^{11}$ Diferentemente do esperado, a lei não apaziguou inúmeras situações conflitantes. Uma das mais graves incongruências das políticas protecionistas (ambientais e indígenas) ocorre, por exemplo, quando o órgão público federal ou estadual responsável declara uma área como sendo de conservação ambiental, superpondo-a a uma área indígena, pressupondo que a convivência das duas situações se dê harmoniosamente e sem conflitos. Frequentemente, o que ocorre é o oposto disto. A sobreposição de uma unidade de conservação sobre uma terra indígena, longe de duplicar a proteção de um determinado território, muitas vezes introduz ali o gérmen do conflito. São inúmeros os casos como este, que mais confundem que auxiliam, seja a política indigenista, seja a ambiental. A condição de unidade de conservação ambiental (UC) confere à terra indígena um uso novo, diferente e, muitas vezes, conflitante com o modo habitual de vida dos índios e ferindo o direito originário que lhes foi conferido pela Constituição. E não são raros esses casos; há pelo menos 55, dos quais 31 são UCs de uso sustentável, 23 são UCs de proteção integral, e num caso ocorre a sobreposição de uma UC de uso sustentável e uma de proteção integral sobre uma terra indígena (ROLLA; RICARDO, 2004:592). A situação é mais grave quando uma unidade de proteção integral se sobrepõe à terra indígena, dado que nela não pode haver alteração do habitat pela ação humana e assim, a caça, a pesca e o extrativismo vegetal não podem ser praticados; e é especialmente dessas atividades que os índios sobrevivem e secundariamente da roça e de outras atividades produtivas complementares. Mas, nas unidades de uso sustentável (mesmo quando não sobrepostas) a situação também não 
é pacífica, porque as populações tradicionais e outras não indígenas (como colonos), que até então desenvolviam atividades na área se sentem cerceadas em seus direitos. Uns poucos exemplos ilustram essas complexidades.

A terra indígena Yanomami, como outras, estava protegida pela Constituição de 1988, como terra de posse imemorial. Contudo, em 1989 havia sido invadida por quase quarenta mil garimpeiros, de maneira que no ano seguinte foram autorizadas três áreas para uso por cooperativas de garimpeiros; posteriormente, elas foram canceladas pelo mesmo Governo Federal, após a morte de quase 1/5 da população indígena, face ao fato de que os garimpeiros carregam consigo alguns males do mundo "civilizado", como o mercúrio e a malária, dos quais os índios não conseguem se defender. Em 2005, novamente os garimpeiros voltam às terras Yanomami trazendo novas doenças. Correspondência dirigida ao Ministro da Justiça e ao Ministério Público Federal pela Fundação Nacional da Saúde/Distrito Sanitário Especial Indígena Yanomami e Ye'kuana denuncia o fato e pede socorro, dado que a situação havia saído de controle quanto às condições sanitárias e ao número de garimpeiros entrados na área. ${ }^{12}$

No final da década de 1990, um decreto presidencial definiu a extensão da terra indígena, mas ignorou e não equacionou o fato de que dentro dela já haviam sido criadas anteriormente duas florestas nacionais e um parque nacional, esta última, uma unidade de uso incompatível com a vida indígena. Uma floresta nacional permite a exploração madeireira, o que já leva a conflitos, não só devido à interpretação que certos grupos (como os Yanomami) dão à floresta, mas também pela abertura de estradas, entrada de máquinas pesadas e outras alterações necessárias à exploração florestal; além disso, a caça, a pesca e outras atividades tradicionais dos índios são interditadas em parques nacionais, embora elas não costumem abalar o ecossistema porque o consumo é reduzido.

Situações como essa são frequentes na Amazônia. Na Terra do Meio (extremo sul do Pará, entre dois grandes rios, Xingu e Iriri) concentram-se numerosos grupos e terras indígenas, a saber: as Terras Indígenas Cachoeira Seca, Kararaô, Arara, Baú, Kayapó (parte dela), Mekrañotire, Panará (parte no Pará e parte em Mato Grosso), Caiabi, Curuá, Xipaia, Munduruku, Sai Cinza e outros grupos situados em terras menores como Pimental, São Luís do Tapajós, Praia do Índio e Praia do Mangue, as duas últimas muito próximas da cidade de Itaituba, no Pará ${ }^{13}$. Além desses grupos indígenas, na Terra do Meio registram-se 5 Áreas de Proteção Ambiental (APA), duas Reservas Extrativistas (RESEX), sete Florestas Nacionais (FLONAs) e um Parque Nacional, compondo um complexo quadro de gente vivendo em terras sobrepostas e leis conflitantes.

Acresce que os cadastros de terras dos órgãos federais - Funai, Incra, Ibama e outros - não se conectam uns com os outros, ainda que pertencendo à mesma esfera de governo. E menos ainda com os cadastros dos órgãos de terra estaduais. Este 
fato provoca novas sobreposições em cima das já existentes, agora envolvendo unidades de conservação estaduais, criadas por instituições diferentes, dando a elas usos distintos e, novamente, em muitos casos, antagônicos. Segundo o Ministério do Meio Ambiente, perto de um terço das áreas de conservação sofre problemas de sobreposições e, na maior parte dos casos, os usos legalmente permitidos por um ato legal competem com aqueles autorizados pelo de outra instituição sobre a mesma área. Do ponto de vista legal, a matéria é ainda apresenta pontos obscuros.

Entendo que, se o $\S 1^{\circ}$ do Art. 231 da Constituição dispõe que são terras indígenas “[...] d) as necessárias a sua reprodução física e cultural, segundo seus usos, costumes e tradições"; e que, da mesma forma, a Lei no. 6001 (Estatuto do Índio) não foi revogada, e seu artigo 22 estabelece caber "aos índios ou silvícolas a posse permanente das terras que habitam e o direito ao usufruto exclusivo das riquezas naturais e de todas as utilidades naquelas terras existentes", a se levar em conta a hierarquia das leis, os atos legais posteriores e de nível hierárquico inferior que vedam tais práticas (caça, pesca, extrativismo vegetal) passam a ser nulos, sendo permitidas tais atividades.

No caso da ADI-MC 3540-1-DF. Relator: Min. Celso de Mello. Diário Oficial da União de 03.02.2006, o STF levou em conta o art. $225 \S 1^{\circ}$, III da Constituição, que estabelece o direito dos originário índios, pelo que, entendeu que as Unidades de Conservação criadas posteriormente são nulas. Entretanto, esclarece o relator que aquela decisão resguarda somente a terra indígena já homologada (FISHER, 2007).

Fisher (op.cit.) menciona ainda outras posições sobre a matéria. A Funai, organizações e movimentos de defesa dos direitos indígenas e antropólogos defendem que todos os atos legais restringindo os direitos indígenas (o que inclui as Unidades de Conservação) são nulos, face ao que dispõe o art. 231 da Constituição. Mas, Carlos F. Marés de Souza Filho (SOUZA FILHO, 1998, p. 148, apud FISHER) alerta para o fato de que há lugares nos quais a preservação deve ser mantida e que, além disso, eles são anteriores à ocupação indígena. É o caso de "sítios arqueológicos e paleontológicos e cavidades naturais [...], a primeira fundamental à cultura e a última à natureza $[\ldots]$ ”.

O Ibama dispõe a matéria em duas situações distintas: (a) no caso das terras indígenas já homologadas, em virtude do $\S 6^{\circ}$ do art. 231, as partes das unidades de conservação sobrepostas às indígenas devem ser consideradas nulas; (b) no caso das partes das unidades que se sobrepõem a terras não homologadas, prevaleceria a hierarquia das leis.

\section{A terRa indígena No DiReito bRASILEIRO RECENTE}

Atualmente, as ações governamentais concernentes à terra indígena refletem a influência de uma política indigenista pendular e inconstante do Estado brasileiro, que oscila sob a influência maior ou menor de determinados segmentos da sociedade, que 
pressionam num sentido ou noutro, dependendo do momento histórico em que vive o país e dos interesses dos grupos hegemônicos.

Embora a Constituição/88 estabeleça que as terras indígenas são aquelas tradicionalmente habitadas por eles, aquelas onde desenvolvem atividades produtivas e aquelas necessárias à sobrevivência física e cultural dos índios (art. 231); e no $\S 4^{\circ}$ do mesmo artigo mencione que os direitos dos índios sobre essas terras são imprescritíveis, a questão não é tão simples quanto o dispositivo legal pretende. E o exercício do Direito quanto ao tema exibe os caminhos e, também os descaminhos que uma ação pode tomar. Para uma análise mais completa, revendo os direitos dos índios desde o passado aos dias atuais, ver Souza Filho (SOUZA FILHO, 2004, 2006). A primeira dificuldade a enfrentar no que concerne à definição do espaço que constituirá uma terra indígena reside na comprovação de que ela é tradicionalmente ocupada pelo grupo e este é um ponto nevrálgico que tem provocado muitas questões na justiça.

O crescimento, a intensa mobilidade espacial da população brasileira e a rápida expansão da fronteira econômica na Amazônia tornam as terras indígenas sujeitas a invasões de toda a ordem, especialmente em decorrência da prática dos índios de deixar as terras por 20/30/40 anos em descanso, enquanto aguardam a recuperação da natureza. Esta prática vulnerabiliza as terras porque configura para fazendeiros, colonos, madeireiros, garimpeiros e outros que nelas pretendem se estabelecer, como se as terras estivessem abandonadas, o que não é o caso. O problema se agrava, sufocando os reclamos dos índios porque, dada a condição de minoria étnico-cultural, seus interesses se afiguram como menores ou secundários frente aos interesses econômico-financeiros da União, como a exploração de minérios (mas este não é o único caso), que gera recursos considerados necessários ao equilíbrio das contas nacionais, embora represente uma flagrante ameaça à integridade cultural e física dos índios da região.

Embora os direitos às suas terras sejam imprescritíveis, é preciso que os índios comprovem que as terras então ocupadas por terceiros, lhes pertenceram no passado, o que nem sempre é fácil ou possível quando outras atividades já se fixaram sobre elas, destruindo vestígios de uma cultura que não se caracteriza por construções físicas duradouras. Foi o que sucedeu com os índios Tembé, no Pará (e com muitos outros), que já vinham perdendo sucessivas parcelas de terra para posseiros que disputavam com eles partes das terras, além de pequenos e médios produtores rurais. A situação agravou-se quando a prefeitura municipal construiu uma estrada nas bordas da reserva, possibilitando a entrada de madeireiros. E tornou-se crítica quando o Incra instalou um assentamento dentro da reserva, que já estava demarcada desde a década de 1940. Face à impossibilidade de manterem nas parcelas reduzidas de terra a forma de vida anterior, acabaram por se converter em agricultores pobres.

Na justiça, a situação é igualmente difícil. Aí também, dois estatutos legais incidem sobre a terra - a posse agrária e a posse indígena e, com frequência um terceiro - relativo às áreas de proteção ambiental - se adita aos dois anteriores. 
Os índios detêm a posse do solo e da cobertura vegetal das terras em que vivem, tendo, na condição de posseiros, direitos condicionados sobre elas, enquanto a União detém o domínio sobre o solo (terras) e o subsolo, sendo assim, proprietária legal de ambos. Mas, a tensão estabelecida em torno da terra indígena não se esgota na decisão quanto ao uso do solo e o usufruto da natureza que lhe recobre. Ela se desdobra em pelo menos dois níveis: o primeiro diz respeito ao solo, envolvendo a natureza visível, em que vivem os índios, já referido anteriormente; o outro se refere ao subsolo que, se não apresenta interesse direto para os índios, os afeta profundamente, na medida em que o subsolo interessa a garimpeiros e a grupos mineradores nacionais e internacionais.

A terra indígena tem sido objeto de contestação permanente por inúmeros setores da sociedade, em especial, o agrícola exportador (mas não apenas ele), o minerador, segmentos conservadores da sociedade, ligados a atividades econômicas ou não, o que inclui incontáveis profissionais liberais e amplos segmentos da classe média. Têm eles, de uma forma ou de outra, e fundados em razões diversas, defendido a apropriação privada das terras indígenas e uma destinação delas mais diretamente articulada ao mercado. A exploração do subsolo (mineração e garimpos) e dos recursos hídricos (inclusive para fins energéticos) em terras indígenas requer autorização concedida pelo Congresso Nacional, "ouvidas as comunidades afetadas, ficando-lhes assegurada a participação nos resultados da lavra, na forma da lei” (Art. 231, § $3^{\circ}$ ). Mas, apesar da Constituição resguardar o direito dos índios às suas terras, a realidade concreta tornaas vulneráveis atingindo-as nos dois níveis - solo e subsolo. Em 1996 o Governo Federal, através do Decreto-lei no. 1775, passando ao largo do disposto na Carta Magna, retrocede em relação à matéria e, com uma simples mudança em procedimentos administrativos, abre possibilidades para inúmeros questionamentos quanto ao reconhecimento, à demarcação e à regularização de terras indígenas.

É que, no art. $2^{\circ}, \S 8^{\circ}$, o referido decreto dispõe que, desde o início do procedimento demarcatório os mais diversos interessados podem manifestar-se, apresentando razões instruídas com as provas pertinentes. Dessa forma, títulos dominiais, laudos periciais, pareceres, declarações de testemunhas, fotografias e mapas, podem servir, não apenas como motivo para pleitear indenização, demonstrar vícios no processo, mas também para questionar áreas indígenas, inclusive aquelas já homologadas. Assim, na prática, as terras indígenas sobre as quais a Constituição estabelece direitos imprescritíveis, ficam susceptíveis de questionamentos de várias ordens, da etapa inicial de novas demarcações até aquelas já homologadas anteriormente.

\section{Io CONSIDERAÇÕES FINAIS - POR UM NOVO ETHOS SOCIAL E JURÍDICO PARA PENSAR OS ÍNDIOS}

Pensar o desenvolvimento do Brasil e da Amazônia (onde se situam mais de 90\% das terras indígenas), e numa forma nova de alcançá-lo, implica em transitar no meio 
dessa intrincada rede de interesses e de relações, o que não é fácil para nenhuma das partes nela envolvida. Mas a sociedade brasileira e da região amazônica precisam fazer novos percursos históricos na busca do desenvolvimento, sem encarar índios e outras populações tradicionais como bárbaros ou atrasados, nem tampouco como obstáculos em seu caminho. Bárbaros são aqueles que não reconhecem nem respeitam a humanidade e a individualidade do outro em sua diferença. Ou ainda "[...] o verdadeiro bárbaro é aquele que acredita na barbárie do outro" (WOLFF, apud NOVAES, 2004, p.42).

Ao invés disso, um novo conceito de desenvolvimento deve incorporar o direito que têm todas as coletividades de expressarem amplamente e em sua plenitude as particularidades que as caracterizam; o direito às várias gerações futuras de usufruir e de apreciar a natureza ímpar da região; de encarar populações tradicionais, natureza e direitos humanos como aliados na construção de uma sociedade multicultural e mais humanizada. ${ }^{14}$

Walzer (WALZER, 2003, p. 22), entende que numa sociedade plural não pode haver uma justiça única e um único critério legal para agir. E isto fica claro quando o mesmo diz que "uma distribuição é justa ou injusta em relação aos significados sociais dos bens de que se trate”. Ora, a terra para os índios tem um valor, uma representação, um significado cultural e histórico muito diferente da simples terramercadoria que a mesma tem para a sociedade capitalista. Daí porque ela não pode ser tratada no âmbito da Justiça, em nenhum caso, como um equivalente da terra como valor de mercado ou da terra como insumo na produção de lucros futuros. Mas ela o é, frequentemente, como decorrência da visão de mundo e da concepção de sociedade de quem decide. E, sobretudo, do tipo de racionalidade prevalecente de quem assume uma ação decisória - racionalidade capitalista, instrumental, de mercado, ou humanista e solidária. Vale lembrar Lévy Strauss (STRAUSS, 1993), ao mencionar que o verdadeiro conflito do encontro de diferentes culturas reside na forma de conceber e de lidar com as diferenças. Este é um primeiro ponto.

O segundo, decorrente do anterior, diz respeito às decisões quanto às terras indígenas no âmbito do Judiciário. Um exemplo é ilustrativo disso. Desde os anos 80 a construção a hidrelétrica de Belo Monte (no Pará/rio Xingu), vinha sendo adiada por falta de recursos; após a crise energética do final da década de 1990 entrou na pauta das prioridades. A usina hidrelétrica, se construída terá enormes proporções, devendo ser a terceira maior do mundo em potência, com 11 milhões de megawats, e deverá afetar a vida de vários grupos indígenas; prevê-se grandes danos ambientais, prejudicará sítios arqueológicos importantes e, se seguir o exemplo das demais, acabará deixando milhares de famílias desabrigadas ou migrantes desempregados após o término dos serviços de desmatamento e obras civis. Além disso, os benefícios para a região são irrisórios (no caso de Tucuruí, a maior parte da energia é subsidiada para as grandes mineradoras e os municípios no entorno ficaram altamente prejudicados ${ }^{15}$ ). 
E, em meio a pouca discussão entre os interessados e as partes afetadas e muitos protestos, o Executivo vem lutando na justiça pelo direito de construí-la. Como as experiências da construção de hidrelétricas na região, tem sido desastrosas sob todos os pontos de vista - social, econômico, ambiental e mesmo quanto à utilidade (a de Balbina é praticamente inservível), a de Belo Monte, pela magnitude do projeto e dos impactos, tem sido a mais polêmica.

O Ministério Público Federal, movido por instituições de defesa dos direitos dos índios, populações tradicionais e populações afetadas, entrou com ação (na verdade com 3 ações) na Justiça Federal tentando impedir a continuidade dos trabalhos que estavam sendo feitos sem obediência aos trâmites legais, e também, alegando questão maior (de direitos humanos). Curiosamente, os estudos até então realizados mencionavam esforços para preservar os tabuleiros de tartarugas (praias de desova no rio Xingu), mas em nenhum momento referiam-se às várias etnias que vivem na área a ser inundada ou sob sua área de influência, às populações ribeirinhas e outras.

A Justiça Federal acatou a ação de embargo (e não é a primeira e talvez nem seja a última, já que ainda cabem recursos ao Superior Tribunal de Justiça e ao Supremo Tribunal Federal), mas em seguida os estudos foram sendo liberados. No curso do processo vários outros problemas surgiram, seguidos de novas ações e novos recursos. Ações de embargo, liberação, embargo, liberação, etc vêm sendo sucessivamente interpostas, removidas e renovadas ao longo de anos de luta judicial travada entre Governo Federal (Executivo), Justiça Federal, índios e organizações de defesa dos índios, movimentos de remanejados de barragens e outros segmentos. Em março de 2006, a Justiça Federal cancelou a liminar que impedia a realização de estudos ambientais, de engenharia e outros, necessários à implantação da hidrelétrica, alegando necessidade de aumentar o fornecimento de energia, permitindo, assim, o prosseguimento dos estudos visando a execução das obras. Posteriormente foi embargada e em 2009 novamente liberada.

Estudos realizados por cientistas ligados à área de energia elétrica têm divulgado amplamente e sem resultados, a possibilidade de uso de outras fontes de energia em substituição a este (quando seu uso não for aconselhável), como o gás natural, do qual o Brasil é um dos maiores detentores de reservas; ou ainda, através da renovação das redes de transmissão e distribuição de energia que, pela sua ancianidade, provocam enormes perdas de energia, que poderiam ser evitadas, compensando grandemente as possíveis faltas de energia (ANEEL, apud ARAÚJO, 2005), ${ }^{16}$ o que resolveria vários problemas simultaneamente. Mas igualmente, eles não foram levados em conta, face ao interesse empresarial que estimula e pressiona em favor da construção de hidrelétricas. Novos estudos apontaram mais dois aspectos negativos da hidrelétrica: seu alto custo (cerca de 19 bilhões, segundo o jornal O Estado de São Paulo, 21.04.2010, caderno Economia, p. B6) e o fato de que a mesma ficará 4 meses praticamente sem funcionar devido ao período de estiagem anual na Amazônia, que 
provoca a seca do rio Xingu. E, em meio a críticas e protestos, idas e vindas do Judiciário nas várias instâncias, seguidas de estudos científicos demonstrando os equívocos e riscos do projeto, a hidrelétrica é considerada como superior ao direito das populações e aos danos ambientais previstos.

A forma como os índios são vistos face ao projeto fica evidente quando se analisa alguns trechos da sentença que revogou o pedido de suspensão de uma das 3 ações civis públicas interpostas pelo MPF: ${ }^{17}$

[.. ] os interesses indígenas não poderão jamais soterrar o interesse público nacional. [...] o índio é só mais um brasileiro e assim deverá ser tratado. [...] se o Brasil não incluir os povos indígenas em um processo de integração (respeitando-se os aspectos culturais envolvidos), outros países o farão. [...] sob o pretexto de serem 'desvirtuados culturalmente', estas pessoas (os índios) são, na prática, submetidas a condições precárias de habitação e saúde, não lhes sendo permitido sequer terem noção dos direitos que possuem. E sugere, mais uma vez, a integração dos índios à sociedade para que tais culturas [...] sejam integradas e não petrificadas.

Portanto, a ideia de integração, a ideologia do progresso da região (que os números desmentem), estão muito presentes no Judiciário e em todos os níveis. Daí porque o projeto segue sem grandes alterações, passando ao largo da (já legalmente) reconhecida multiculturalidade brasileira. O Ministro-relator do processo Raposa Serra do Sol, citado neste artigo, ainda no mesmo voto relativo à matéria, menciona que os índios brasileiros não precisam se apoiar em tratados internacionais para resguardar seus plenos direitos porque:

[...] o nosso Magno texto federal os protege por um modo tão próprio quanto na medida certa [...] É a nossa Constituição que os índios brasileiros devem reverenciar como sua carta de alforria no plano sócio-econômico e históricocultural, e não nessa ou naquela declaração internacional de direitos, por bem intencionada que seja.

Se o ministro tem razão ao dizer que a legislação brasileira assegura plenos direitos aos índios (e seu ponto de vista está longe de ser isolado), como explicar decisões tão distintas do Judiciário sobre uma mesma questão?

No meu modo de ver a questão, se as dúvidas e discordâncias entre membros do Judiciário, nas mais diversas instâncias, não decorrem da legislação - posto que esta seria abrangente o suficiente para albergar as mais variadas situações -, então, há que se reconhecer a existência de uma fragilidade no ethos jurídico-social em que se apóiam os executores do direito. Não consigo ver no presente momento da vida brasileira, face à diversidade de decisões quanto aos direitos indígenas, no âmbito do 
Judiciário, um ethos claro e inequívoco, capaz de proteger amplamente o índio e sua terra, entendendo-a a um só tempo como herança cultural e condição de sobrevivência social do grupo, e sem a qual, a etnia se vê desprovida de um elemento fundamental de sustentação. Ao contrário, vejo uma justiça que tem oscilado na questão, e que decide ora fundada em princípios humanistas mais duradouros, que buscam uma justiça compreensiva e plural; ora influenciada por uma lógica desenvolvimentista sem nuances e atenuantes e sujeita à variação das conjunturas sócio-econômicas e políticas que afetam o País. No caso de Belo Monte, tem ficado claro que os órgãos do Executivo responsáveis pelo projeto tem saltado etapas, abreviado outras legalmente instituídas e aberto poucos canais de comunicação e negociação com os atingidos; mas o projeto prossegue incólume, apesar das várias ações interpostas e sucessivamente rejeitadas.

É preciso lembrar que as teorias sobre a justiça social não podem estar desacompanhadas de um ethos próprio que possibilite sua concretização. No caso brasileiro, as permanentes controvérsias nas decisões do Judiciário, com deliberações seguidas de embargos e liberações em quase todos os casos de grande impacto sobre minorias, obrigam a inferir pela necessidade de se estabelecer um novo ethos (quando se trata da terra indígena), capaz de penetrar profundamente nos órgãos do Estado, orientando, assim, o exercício quotidiano da ustiça em todas as instâncias, bem como a prática administrativa dos órgãos públicos quanto aos direitos das minorias.

Sucessivas decisões em favor e contrárias à execução de obras, fundadas em interpretações jurídicas diferentes, mas baseadas nos mesmos dispositivos legais, levam à conclusão necessária de que existe uma lacuna ética e epistemológica quanto à forma de pensar a cultura indígena pelo judiciário, o que possibilita avanços e recuos que, mesmo involuntariamente, provocam insegurança, pânico e desesperança no seio das minorias. Daí porque postulo a necessidade do estabelecimento de um novo ethos jurídico e social, a ser desenvolvido pelo Judiciário, e em especial pelo STF, de forma a irradiar por todo o sistema jurídico um novo sentido de democracia - amplo, profundo, sem ambiguidades, apoiado em novos princípios de sociabilidade e igualdade -, capaz de derramar sua grandeza social sobre as minorias, mesmo aquelas que, como os índios, desde séculos se refugiaram nos confins das matas amazônicas fazendo delas seu último refúgio.

Um terceiro ponto diz respeito à sociedade nacional e à identidade indígena. Dois aspectos precisam ser destacados: fazer parte da sociedade nacional como protagonista de sua própria vida não deve implicar para os índios na perda da própria identidade. Ao contrário, é preciso compreender que a riqueza de um país não está representada nos seus recursos naturais, especialmente os minerais, como pensavam os teóricos mercantilistas do passado; ou como os liberais clássicos dos quais Adam Smith foi o mais destacado (séc. XVIII), segundo o qual a riqueza das nações estava na produção, na iniciativa individual dos empresários e no mercado que, com sua mão invisível, zelaria 
pelo bem-estar social. Ao contrário, um dos ganhos do pensamento filosófico do século XX foi nos fazer compreender que a verdadeira riqueza das nações consiste em derramar sobre os cidadãos de cada país uma democracia plena, enraizada numa justiça social profunda. Assim, ser verdadeiramente moderno não implica em ser um país rico materialmente, mas em dotar seus cidadãos de uma plenitude de direitos.

Para finalizar, creio caber ao judiciário a iniciativa de explicitar e de imprimir este novo ethos jurídico-social, no cotidiano de suas decisões relativas aos índios e demais grupos minoritários. Este papel concerne especialmente ao Supremo Tribunal Federal por duas razões, pelo menos. Em primeiro lugar, porque o poder que emana do mesmo nas decisões comuns, mas sobretudo, quando se trata de firmar jurisprudência sobre uma questão controvertida como a questão indígena, torna possível fazer com que tais decisões preencham os poros do Judiciário em todas as demais instâncias secundárias, clarificando temas e pacificando querelas, definindo um novo ethos. E, em segundo lugar, cabe ao STF este relevante papel face à respeitabilidade de que se revestem as decisões que dele emanam.

Imprimir um novo ethos em todos os campos do direito e da justiça é, sem dúvida, uma tarefa árdua, difícil e incessante; mas humana e gratificante. A complexidade atual da vida brasileira desafia e exige do Judiciário a responsabilidade de estabelecer um novo pacto social, a ser instituído com o fim de construir uma democracia multicultural, profunda e ampla, para que ela se derrame e se exerça desde as grandes cidades até os rincões mais afastados do poder e da justiça, como os povoados, vilas e aldeias amazônicas. É pugnando no cotidiano contra os interesses e pressões dos grupos econômicos ou conservadores que o Judiciário brasileiro conseguirá outorgar uma cidadania plena e profunda à sociedade - uma sociedade reconhecidamente complexa e plural; que exige do Judiciário um esforço extraordinário para compreender as necessidades distintas de cada grupo social em cada canto do País. É preciso um contrato social moderno, que faça a filosofia do direito descer das páginas dos livros para as folhas dos processos que circulam no Judiciário; missão difícil mas realizável, como demonstrou a Itália nas décadas de 1970 e 1980, quando desencadeou o movimento "Mãos Limpas". Apoiado num novo ethos jurídico-social - que se viabilize pelas vias administrativo-burocráticas do dia-a-dia, o Judiciário conseguirá que as ideias difusas de democracia convertam-se em direitos concretos, capazes de alcançar individualmente cada brasileiro, de qualquer etnia, transformando o Brasil, de fato, num país pluricultural e pluriétnico. Quando alcançar este objetivo, o Brasil poderá se dizer realmente moderno; não pelos avanços tecnológicos que conseguir desenvolver e exibir como resultado da acumulação de capitais e bens materiais diversos; mas como um país que abriga a todos em seu espaço multicultural, diferenciado e igualitário. 


\section{NOTAS}

1 Doutora em Sociologia pelo Institut des Hautes Études de L'Amérique Latine - Universidade de Paris III; Mestre em sociologia pela UNICAMP; Profa. do Programa de Pós-Graduação em Ciências Sociais e do Programa de PósGraduação em Direito, ambos da Universidade Federal do Pará.

2 Dados cadastrais do Incra e IBGE, trabalhados em pesquisa realizada pela FAPESP/UNESP e apresentados no Atlas da Questão Agrária Brasileira, mostram que em 2003/Brasil havia 22 imóveis rurais (registrados) com mais de 100.000 ha; de 500000 a 100000 havia 32; de 20.000 a menos de 50.000 havia 294; e de 10.000 a 20.000 havia 635 imóveis. Os dados não mostram a junção de várias fazendas por um mesmo proprietário, nem as imensas fazendas existentes na Amazônia, formadas com origem em grilagem de terra, que ultrapassam de muito essas dimensões. No ano 2000 somente em terras federais havia 1438 imóveis (pessoas físicas e jurídicas) que somavam 46.156.619 ha com suspeita de grilagem, sendo 479 na Amazônia, somando 24.399.977 ha. (Fonte: Incra: Proj. Coop.Técnica INCRA/FAOProj.UTF/BRA/051/BR; disponível em www.greenpeace.org.bra.perfil.de.prop.rurais.INCRA-FAO.pdf (Acesso em 21.10.2009). A estimativa é a de que nos estados as fraudes sejam muito maiores e mais numerosas.

3 Segundo dados do PNUD/2005 os estados da região apresentavam IDHs muito baixos: Amazonas - 0,780, Pará - 0,755, Amapá - 0,780, Roraima - 0,750, Acre - 0,751, Rondônia - 0,776, Tocantins - 0,756, estando muito próximos dos índices dos estados do nordeste, exceto os do Maranhão e Alagoas, que se apresentavam entre os mais baixos IDHs do Brasil (0,683 e 0,667, respectivamente). Disponível em: www.scrbd.com/doc/6080766-Indice-de-Desenvolvimento - Humano-dos-Estados-Brasileiros. Acesso em: 01.10.2009.

4 O Amazonas sofre menos impactos porque a Zona Franca de Manaus concentra população, emprego e renda, evitando a expansão da fronteira dentro do estado.

5 O total de terras indígenas no Brasil é de 673 (1.099.744 km2, ou 12,92\% de todo o território nacional), das quais 409, ou seja, 98,61\% localizam-se na Amazônia e destas 187 encontram-se em faixas de fronteira. Disponível em: http://pib.socioambiental,org/pt/c/terras-indigenas/demarcacoes/localizacao-e-extensao-das-tis. Acesso em: 01 set 2009 .

6 Os Kayapó da Terra Baú perderam 300 mil ha quando tiveram que assinar em 2003 um Termo de Conciliação e Ajuste de Conduta (HECK; LOEBENS; CARVALHO, 2005). E agora vão ser novamente afetados pela construção da hidrelétrica de Belo Monte, assim como os Juruna, os Xikrin (mais próximos da barragem) e talvez outros que devem ser removidos para outras áreas. Vários grupos tem perdido terras quando, de acordo com o art. $225 \S 1^{\circ}$., III da Constituição, as alterações e reduções de áreas especialmente protegidas (é o caso das indígenas, de quilombolas e outras) só são válidas mediante leis, mas nunca através de acordos ou outro instrumento.

7 Denúncia do prefeito de Óbidos ao jornal O Liberal, Belém, p.5, 30 de maio de 2005, cad. Atualidades.

8 Entrevista realizada com técnicos da Secretaria de Estado de Meio Ambiente do Amapá em 2008.

9 Conforme denúncia da Comissão Pastoral da Terra/Marabá, 2001; In: PINTO, Jax Nildo Aragão. Terra do Meio: estudo de caso na nova fronteira amazônica. Belém: Universidade Federal do Pará, 2005, originalmente apresentado como dissertação de Mestrado no Programa de Pós-graduação em Ciências Sociais, Instituto de Filosofia e Ciências Humanas.

10 A composição do PIB per capita, segundo grandes regiões em 2004 era a seguinte, em milhões: Sudeste: 970.245; Nordeste: 248.445; Sul: 321.781; Centro-Oeste: 132.727 e finalmente a Região Norte com apenas - 93.423. (Fonte: IBGE/Diretoria de Pesquisas/Contas Regionais do Brasil, Tabela 4). Disponível em: http://www.ibge.gov.br/ home/estatistica/economia/contasregionais/2004/notastecnicas.pdf . Acesso em 10.05.2010.

11 A Lei no. 9985/2000 (regulamentada pelo Decreto no. 4.340/2002), cria o Sistema Nacional de Unidades de Conservação da Natureza e divide as unidades em duas categorias: de proteção integral (não podem ser alteradas pela ação humana; são elas: Estações Ecológicas, Reservas Biológicas, Parques Nacionais, Monumentos Naturais e os Refúgios de Vida Silvestre) e de uso sustentável (podem ser manejadas sob critérios estabelecidos; são elas: Áreas de Proteção Ambiental, Áreas de Relevante Interesse Ecológico, Florestas Nacionais, Reservas Extrativistas, Reservas de Fauna, Reservas de Desenvolvimento Sustentável e as Reservas Particulares do Patrimônio Natural). Disponível em: http://www.planalto.gov.br/ccivil_03/Leis/L9985.htm. Acesso em: 01.07.2009. 
12 Texto integral da mesma disponível em: www.ocioambiental.org.nsa/doc 20072005/html. Acesso em 18.10.2010.

13 Consulta direta aos técnicos, arquivos e mapas da Funai-Belém, 2005.

14 Sobre a epistemologia multicultural ver SEMPRINI, Andrea. Multiculturalismo. São Paulo-Bauru: Edusc, 1999.

15 Em 1980, antes da construção da hidrelétrica, a população de Tucuruí era de 61.140 hab. Em 1991 havia alcançado 111.667 hab e a crise de emprego, escola, saúde, segurança e outros serviços era enorme. Fonte: Censos Demográficos 1980 e 1991. R.J.: IBGE. Os índios Parakanã, Araweté e Assurini haviam sido removidos e as populações não índias não haviam sido reassentadas, tal como fixado nos acordos; as populações dos municípios próximos continuavam sem energia da usina porque esta havia sido direcionada para as mineradoras e para Belém e a Eletronorte não havia feito as redes rebaixadoras de energia para atendê-las por considerar anti-econômico, dado o baixo consumo das populações pobres do entorno. Este tem sido o modelo das várias hidrelétricas construídas na região. Dados disponíveis em: http://www.ibge.gov.br/home/ estatistica/economia/contasregionais/2004/notastecnicas.pdf e inúmeras outras fontes.

16 As perdas globais de energia no Brasil em 2005 correspondiam a 15\% do total produzido, sendo a maior parte decorrente da energia dissipada entre a usina e o ponto de fornecimento, das redes de distribuição urbanas e transformadores antigos ou deficientes, de problemas de administração das empresas e de eventuais questões climáticas. ARAúJO, 2007. Fonte dos dados básicos: ANEEL, 2005.

17 Sentença. Proc. 2006.39.03.000711-8 (fl.41,43). Herculano Martins Nacif, Juiz Federal da Vara Única da Subseção Judiciária de Altamira/Pa. In: ARAúJO, op.cit. pp.111-120.

\section{REFERÊNCIAS BIBLIOGRÁFICAS}

ARAÚJO, Antônio Carlos Marques de. Perdas e Inadimplência na Atividade de Energia Elétrica no Brasil. Disponível em: http://www.aneel.gov.br/biblioteca/trabalhos/trabalhos/Tese_AntonioCarlos.pdf. Acesso em: 16 out 2010. Originalmente apresentada como tese de doutoramento: UFRJ/COPPE, 2007.

ALVES, José Augusto Lindgren. Os direitos na pós-modernidade. São Paulo: Perspectiva, 2005.

FAORO, Raymundo. Os donos do poder: formação do patronato brasileiro. São Paulo: Edusp, 1975.

FISHER, Luly R. da Cunha. Os recortes na terra dos "Filhos do Guaraná": implicações jurídicas das sobreposições de Unidades de Conservação na terra indígena Andirá-Maraú. Belém. Seminário Formação Jurídica e Povos Indígenas - Desafios para uma educação superior. 2007. Disponível em: www3.ufpa.br/jurídico/

Os_Recortes_Na_Terra_dos_Filhos_Do_Guaraná. Acesso em: 23 jun 2009.

HECK, E; LOEBENS, F; CARVALHO, P. Amazônia indígena: conquistas e desafios. Estudos Avançados - Dossiê Amazônia Brasileira I. vol. 19, no. 53, jan-abr, 2005.

HORKHEIMER-ADORNO. Conceito de Iluminismo. In: BENJAMIN, Walter; HORKHEIMER, Max; ADORNO, Theodor W.; HABERMAS, Jurgen. Textos escolhidos. São Paulo : Abril Cultural, 1980, pp. 89-116 (Os Pensadores ; n. 48). LÉVY-STRAUSS, Claude. História de Lince. São Paulo: Cia. das Letras, 1993.

LOUREIRO, Violeta R. Amazônia: Estado, homem, natureza. Belém: Cejup, 1992.

MARTINS, J. S. Fronteira - a degradação do outro nos confins do humano. São Paulo: Hucitec, 1997.

ORLOVE, Benjamin; BRUSH, Stephen. Anthropology and Conservation of Biodiversity. Anual Review of Anthropology, vol. 5, 1996, pp. 329-352.

PINTO, Jax Nildo Aragão. Terra do Meio: estudo de caso na nova fronteira amazônica. Belém: Universidade Federal do Pará, 2005. Originalmente apresentado como dissertação de Mestrado no Programa de Pós-graduação em Ciências Sociais, Instituto de Fil. e Ciências Humanas, 2005.

POUTIGNAT, P.; STREIFF-FENART, J. Teorias da etnicidade. São Paulo: Editora daUnesp, 1998.

RIBEIRO, Darcy. Os Índios e a civilização - a integração das populações indígenas no Brasil moderno. Petrópolis: Vozes, 1970.

RICARDO, C. A. (org.). Povos indígenas do Brasil 1991-1995. São Paulo: Inst. Socioambiental, 1996.

(org.). Povos indígenas do Brasil 1996-2000. São Paulo: Inst. Socioambiental, 2000.

ROLLA, Alicia; RICARDO, Fanny. Terras indígenas \&unidades de conservação: o desafio das sobreposições. São Paulo: Instituto socioambiental, 2004. 
526 : DESENVOLVIMENTO, MEIO AMBIENTE E DIREITOS DOS ÍNDIOS: DA NECESSIDADE DE UM NOVO ETHOS JURÍDICO

SCHWARTZMAN, Simon. Bases do autoritarismo brasileiro. Rio de Janeiro: Campus, 1988.

SEMPRINI, Andrea. Multiculturalismo. São Paulo-Bauru: Edusc, 1999.

SOUZA FILHO, Carlos Frederico Marés. Multiculturalismo e direitos coletivos. In: SANTOS, Boaventura de Souza (org.). Reconhecer para Libertar. Porto: Afrontamento, 2004.

SOUZA FILHO, C. F. M. O renascer dos povos indígenas para o direito. Curitiba: Juruá, 2006.

VIDAL, Lux. Morte e vida de uma sociedade indígena brasileira. São Paulo: Hucitec /Edusp, 1997.

WALZER, M. Esferas da Justiça: uma defesa do pluralismo e da igualdade. São Paulo: Martins Fontes, 2003

(Coleção Justiça e Direito).

WOLFF, Francis. Quem é bárbaro? In: NOVAES, Adauto (org.).Civilização e barbárie . São Paulo: Cia das Letras, 2004, pp. 19-43.

Violeta Refkalefsky Loureiro

Rua Augusto Corrêa, n. 1 Guamá - 66035-400

Belem - PA - Brasil violeta.loureirolaig.com.br
Doutora em Sociologia pelo Institut des Hautes Études de L'Amérique Latine - Universidade de Paris III.

Mestre em sociologia pela Unicamp.

Professora do Programa de Pós-Graduaçāo em Ciências Socials e do Programa de Pós-Graduação em Direito da Universidade Federal do Pará (UFPa). 